\title{
Frequent and long-term follow-up of health- related quality of life following allogeneic haematopoietic stem cell transplantation
}

Ulla Frödin, Kourosh Lotfi, V. Fomichov, G. Juliusson and Sussanne Börjeson

\author{
Linköping University Post Print
}

\section{Tweet}

N.B.: When citing this work, cite the original article.

Original Publication:

Ulla Frödin, Kourosh Lotfi, V. Fomichov, G. Juliusson and Sussanne Börjeson, Frequent and long-term follow-up of health-related quality of life following allogeneic haematopoietic stem cell transplantation, 2015, European Journal of Cancer Care, (24), 6, 898-910.

http://dx.doi.org/10.1111/ecc. 12350

Copyright: Wiley: 12 months

http://eu.wiley.com/WileyCDA/

Postprint available at: Linköping University Electronic Press

http://urn.kb.se/resolve?urn=urn:nbn:se:liu:diva-122649 


\title{
Frequent and long-term follow-up of health-related quality of life following allogeneic haematopoietic stem cell transplantation
}

\author{
U. FRÖDIN, RN, MSC, LICENTIATE, Department of Hematology and Department of Medical and Health Sciences, \\ Linköping University, Linköping, K. LOTFI, MD, PHD, ASSISTANT PROFESSOR, Department of Hematology and \\ Department of Medical and Health Sciences, Linköping University, Linköping, V. FOMICHOV, MSC, STATISTICIAN, \\ Regional Cancer Center Southeast, County Council of Östergötland, Linköping, G. JULIUSSON, MD, PHD, \\ PROFESSOR, Department of Hematology and Coagulation and Stem Cell Center, Lund University, Lund, \& \\ S. BÖRJESON, RN, PHD, ASSISTANT PROFESSOR, Department of Hematology and Department of Medical and Health \\ Sciences, Linköping University, Linköping, Sweden
}

FRÖDIN U., LOTFI K., FOMICHOV V., JULIUSSON G. \& BÖRJESON S. (2015) European Journal of Cancer Care Frequent and long-term follow-up of health-related quality of life following allogeneic haematopoietic stem cell transplantation

\begin{abstract}
Health-related quality of life (HRQL) was evaluated in 94 patients undergoing allogeneic haematopoietic stem cell transplantation (HSCT) after myeloablative (MAC, $\mathrm{n}=18$ ) or reduced intensity conditioning (RIC, $\mathrm{n}=76$ ). HRQL was assessed with the EORTC QLQ C-30 during the inpatient period as well as during the following 3 years, i.e. at baseline and 12 times thereafter. Functional status and global quality of life decreased from baseline to weeks 2 and 3, especially role and social functions. Symptoms increased significantly during the first 3 weeks, particularly appetite loss, nausea and vomiting, diarrhoea and fatigue. It took at least 1 year for HRQL to return to the baseline level. The only function that improved significantly 3 years after HSCT was role function. Patients treated with MAC experienced significantly worse HRQL at baseline than patients treated with RIC, as well as more pain, sleep disturbance and appetite loss in weeks 3 and 4. Patients with extensive chronic graft-versus-host disease experienced reduced HRQL. These results provide a clinically useful overview of patients' HRQL during and after HSCT and indicate when they require increased support. The results demonstrate the importance of close follow-ups during the first year after HSCT to improve preventive or supportive interventions.
\end{abstract}

Keywords: quality of life, symptom, stem cell transplantation.

Correspondence address: Ulla Fr€odin, Department of Hematology,

Link€oping University Hospital, SE-581 85 Link€oping, Sweden (e-mail:

ulla.frodin@ regionostergotland.se).

Accepted 7 June 2015

DOI: $10.1111 /$ ecc. 12350

European Journal of Cancer Care, 2015

\section{INTRODUCTION}

Patients receive various conditioning treatments [i.e. chemotherapy with or without total body irradiation (TBI)] before haematopoietic stem cell transplantation (HSCT). The aim of the conditioning regimen is to create space for the transplanted stem cells, to induce immunosuppression and to eliminate the disease (Juliusson et al. 2003; Gratwohl \& Carreras 2012). The conditioning was initially myeloablative conditioning (MAC; Gyurkocza \& Sandmaier 2014), which means high-dose chemotherapy with or without TBI. However, due to serious side effects, only young patients were eligible for HSCT, since severe toxicity increases with age (Socie et al. 2003; Diaconescu et al. 2004). In the late 1990s, reduced intensity conditioning (RIC) was introduced and developed (Bacigalupo et al. 2009; Cremer et al. 2011) with the main purpose of reducing toxicity to allow older people and those with compromised health to benefit from HSCT (Juliusson et al. 2006; Gyurkocza \& Sandmaier 2014). Choice of the MAC or RIC is primarily influenced by various risk factors, for example the stage of the disease and age (Ljungman et al. 2010). It is important to evaluate factors other than treatment response and survival when the treatment strategy is changed. Irrespective of treatment strategy, HSCT has a strong impact on patients' health-related quality of life (HRQL; Larsen et al. 2004; Bevans et al. 2008), with a high risk of different complications, such as graft-versus-host disease (GvHD; Pallua et al. 2010; Braamse et al. 2012).GvHDis a common complication after allogeneic HSCT and is caused by several factors that trigger the activation of donor T cells. The risk of developing acute GvHD is 30-50\% for patients with a related donor and may be higher with an unrelated donor (Bhatia et al. 2007; Apperley\&Masszi 2012). The risk is graded from 1 to 4, where 1 ismild GvHD and 4 is a life-threatening condition involving all three organs (Skin, gut and liver). ChronicGvHDnormally occurs 100 days afterHSCT. Chronic GvHD affects significantly more organs than acute GvHD and is divided into limited and extensive chronic GvHD, depending on the number of organs involved and the severity of the attack on the affected organs (Apperley\&Masszi 2012). This study started in 2001 when RIC was introduced at our department. At that time, none of the previous studies with a prospective and longitudinal design had fully covered the whole inpatient period as well as longterm follow-up in patients receiving MAC and RIC regimes (Decker et al. 1989; Larson et al. 1993; Mcquellon et al. 1997, 1998; Zittoun et al. 1999). Thus, the overall purpose of the present study was to explore the whole inpatient period and the following 3 years to evaluate HRQL with both MAC and RIC regimes over time. Specific aims were to identify symptoms during treatment, how they develop over time and how long they persist after HSCT. 


\section{METHODS}

\section{Design}

This is a quantitative, descriptive, prospective and longitudinal study following patients during their entire inpatient period and up to 3 years thereafter.

\section{Study population}

During the inclusion period from September 2001 to January 2008, 110 patients were accepted for allogeneic HSCT. The inclusion criteria were adult patients receiving their first allogeneic HSCT and being able to understand the Swedish language. Three patients were not included due to language problems, seven due to a second HSCT, two due to syngeneic HSCT, one was too ill and three declined participation, which gives a study population of 94 patients.

\section{Data collection procedure}

All patients who met the inclusion criteria were invited to participate in the study when they arrived at the transplant unit. All patients received verbal and written information about the study from one of the authors (UF). After oral informed consent, the patient received the European Organization for Research and Treatment of Cancer Quality of Life Questionnaire (EORTC QLQC30) (Aaronson 1993). A total of 13 questionnaires per patient were distributed at baseline (before the start of conditioning), once a week during weeks $1-4$, once a month during months 2 and 3 , once during month 6 , and then once every 6 months up to year 3 after HSCT. After discharge, questionnaires were sent to the patients together with a prepaid return envelope. The questionnaires were distributed and collected by one of the authors (UF). Late responders received new questionnaires as a reminder after 2-4 weeks. Questionnaires answered later than a month after deadline were not included in the analysis.

\section{Conditioning treatment}

Patients received conditioning therapy according to disease and risk level (stage of the disease, age of the patient, time interval from diagnosis to transplantation, Karnofsky score, histocompatibility and sex combination between donor and patient; Ljungman et al. 2010; Table 1). The patients treated with RIC received combinations of drugs with known effects against the specific disease entities at established doses; doses intended to reduce toxicity without impairing efficacy. Patients with acute leukaemia and aggressive lymphomas received FAM (Fludarabine, ARA-C, Melphalan; some patients with an addition of mitoxantrone and idarubicin) or FluBu (Fludarabine, Busulphan). Multiple myeloma (MM), lymphoproliferative and other diseases were treated with FCM (Fludarabine, Cyclophosphamide, Melphalan). Patients with aplastic anaemia received fludarabine, cyclophosphamide and antithymoglobulin (ATG). Most patients received subcutaneous alemtuzumab or intravenous ATG to prevent rejection and reduce the risk for GvHD (Table 1). Regardless of the conditioning regimens, most patients received cyclosporine A together with mycophenylate mofetil as GvHD prophylaxis (Juliusson et al. 2003).

\section{Measuring health-related quality of life}

To measure HRQL, the EORTC QLQ-C30 questionnaire (version 3) was used (Aaronson 1993). The instrument has been translated and validated in 81 languages and used in more than 3000 studies worldwide. It consists of 30 items divided into three major domains: functional status, symptom status and global health/QoL. Functional scales consist of physical function (five items) and apply to the ability to manage daily life, for example if the patient has trouble executing strenuous activities, such as taking long/short walks, if the patient must sit/lie down during the daytime and if they can manage their own personal hygiene. Role function (two items) involves areas related to work, daily activities and leisure activities. Emotional function (four items) covers areas of tension, anxiety, irritability and depression. Social function (two items) concerns whether the patients' physical function or medical treatment has interfered with their family life or social activities. Cognitive function (two items) is about problems concentrating and remembering. There are three symptom scales that measure fatigue (three items), which addresses whether the patient needed rest, felt weak and has been tired, or experienced nausea and vomiting (two items) and pain (two items), where the patient is asked to answer whether he/she has had pain and whether his/her daily activities were affected by pain. There are five single items measuring dyspnoea, insomnia, appetite loss, constipation and diarrhoea, and one item measuring financial impact. Global health/QoL consists of two items, the first question concerns overall health and the second question concerns the overall QoL. The functional and symptom scales/items comprise four levels (response alternatives: not at all, a little, quite a bit, very much). Overall QoL is measured on a 7-point scale, ranging from 1 (very poor) to 7 (excellent). For all items in the instrument, the patient makes an assessment of the past week. All scales and items are transformed according to the EORTC scoring manual into a 0- to 100-point scale. Higher scores for functional scales and QoL status indicate a high level of function and higher scores on the symptom scales and single items indicate more severe symptoms or impairments.

\section{Statistical methods}

The results are presented using descriptive statistics: count, proportion, mean and standard deviation (SD). Missing data in individual questionnaires were processed according to the EORTC scoring manual (Fayers et al. 2001). Since a large proportion of patients (47\%) died during the study period, separate data analyses were made for the 34 patients who participated in all 13 follow-ups from baseline over the 3-year period. Furthermore, mean differences between baseline and the follow-ups in week 3, month 3 , year 1 and 3 were assessed as a complement to the analysis performed in the entire patient 
group. The Wilcoxon signed-rank test was performed in the total study population to test for differences in every item between baseline and the follow-ups in weeks 2 and 3 and year 3 , and to test for differences in every item between the patients answering the questionnaire at week $3(n=86)$, month $3(n=80)$, year $1(n=50)$ and $3(n=34)$ with the baseline value. A P-value of $<0.05$ was considered significant. Regression analyses adjusted for gender and age were applied separately each time when differences between and within groups were examined (Hjermstad et al. 1998). When comparing groups, a $\mathrm{P}<0.01$ was regarded as significant. GvHD was scored according to the EBMT handbook (Apperley \& Masszi 2012). Clinical data including GvHD were extracted retrospectively from medical records (Table 1). All statistical analyses were performed using IBM SPSS/PASW Statistics18 USA.

\section{Ethical consideration}

In accordance with the Declaration of Helsinki, patients received verbal and written information about the study stating that participation was voluntary and confidentiality was guaranteed. The patients who met the inclusion criteria gave their verbal consent to participate in the study. The study was approved by the Ethics Committee at Linköping University (Dnr 03-366).

\section{RESULTS}

The mean age of the 94 participants was 48 years, with an equal distribution of men and women. The majority of the patients had leukaemia (54\%), an unrelated donor (55\%), and were treated with RIC (83\%). At HSCT, the disease was in complete remission (CR) in $61 \%$ of the patients, there was no CR (i.e. partial remission or minor response) in $15 \%$, progressive disease in $7 \%$, chronic phase in $7 \%$, refractory in $3 \%$, sensitive disease in $2 \%$, aplasia in $2 \%$ and in one patient the disease status was unknown at the HSCT (Table 1). The study population was reduced by $60 \%$ from baseline to the 3-year follow-up (Fig. 1).The primary reason for not completing the study was death (47\%), caused by relapse (30\%), infection (32\%) and GvHD (25\%). The majority (92\%) of the 38 patients who remained in the study at the 3 -year follow-up were in CR. The number of missing individual questionnaires amounted to $4 \%$, with one missing questionnaire at baseline, and four at the 3-year followup. The patients who died during the study $(\mathrm{n}=44)$ had significantly lower values at baseline than the patients who survived over the 3-year period $(\mathrm{n}=34)$ with regard to physical function $(60$ vs. $88, \mathrm{P}<0.01)$, global health status/ QoL ( 64 vs. $77, \mathrm{P}$ $<0.01$ ), fatigue ( 38 vs. $23, \mathrm{P}<0.01)$, appetite loss ( 17 vs. $2, \mathrm{P}<0.01)$, nausea and vomiting $(13$ vs. $1, \mathrm{P}<0.01)$. The survivors' results were almost identical to those of the entire study population regarding HRQL during the inpatient- and follow-up period. To illustrate this, the results are provided in a separate graph in Figures 2 and 3.

\section{Functional status}

The patients reported a significant reduction in physical, social, role, cognitive and emotional function during the first 3 weeks $(\mathrm{P}<0.01)$. Patients' physical, emotional, cognitive and social function started to improve already at week 4 , but for role function there was no improvement until the 2-month assessment (Fig. 2). Patients still experienced a significant impact on physical, role, cognitive and social function at the 3- month assessment, with the exception of emotional function which had returned to the same value as at baseline $(\mathrm{P}<0.05$; Table 2). Approximately, 6 months after transplantation, role function had improved to almost the same value as before transplantation. Physical, cognitive and social function had improved to the same value as at baseline at the 1-year assessment (Fig. 2). Role function was the only function that had improved significantly at the 3-year follow-up compared to baseline $(\mathrm{P}<0.05$; Table 2$)$.

\section{Symptom status}

The patients experienced a statistically significant deterioration in nearly all symptoms during the first 3 weeks from baseline. The most troublesome ones were appetite loss, nausea and vomiting, diarrhoea, fatigue, sleep disturbance and pain $(\mathrm{P}<0.05$; Fig. 3). Dyspnoea was a greater problem after HSCT and reached the maximum value 2 months after HSCT (Fig. 3). Patients still experienced significant problems with almost all symptoms at the 3 - month assessment $(\mathrm{P}<0.05$; Table 2$)$. Baseline values were nearly reached at the 1 -year assessment, but there were still some significant differences in nausea, vomiting and appetite loss (Table 2; Fig. 3).

\section{Overall/global QoL}

The patients experienced a deterioration in overall/global QoL from a mean of 69 points at baseline to 37 points at week 3 (P $<0.05$ ), with a gradual return to the baseline value 1 year after HSCT (data not shown). Thereafter, the overall QoL assessment remained stable over the following years.

\section{Differences between MAC and RIC}

Patients treated with MAC had a 6-day longer inpatient period and a 3-day longer period of neutrophil counts $<0.59$ 109/L than patients treated with RIC. Patients in the MAC group were more affected by acute GvHD, but less by chronic GvHD, compared to the patients in the RIC group. Among the patients treated with MAC and RIC, 69\% MAC and 42\% RIC died. At baseline, patients treated with MAC had significantly worse scores with regard to fatigue (46 vs. $27, \mathrm{P}<0.01$ ), nausea and vomiting (19 vs. $4, \mathrm{P}<0.01)$ than patients treated with RIC. At week 3 , patients treated with MAC had worse scores with regard to pain ( 52 vs. $29, \mathrm{P}<0.01)$, and sleep disturbances $(65$ vs. $36, \mathrm{P}<0.01)$ than patients treated with RIC. At week 4 , the same patients had worse scores with regard to appetite loss $(72$ vs. $39, \mathrm{P}<0.01)$ and diarrhoea $(40$ vs. $13, \mathrm{P}<0.01)$ than 
patients treated with RIC. At month 2, the differences between the MAC and RIC groups had diminished. After month 3, the number of MAC patients was 7 or fewer, and thus further testing between MAC and RIC was not performed (Fig. 4).

\section{GvHD and HRQL}

Acute GvHD was reported in $57 \%$ of the patients. Grade 1 and 2 affected $39 \%$ of the patients. Grade 3 and 4 affected $18 \%$ of the patients. Chronic GvHD was reported in $53 \%$ of the patients. Limited chronic GvHD affected $20 \%$ of the patients, and extensive chronic GvHD affected 33\% of the patients (Table 1). There were no significant differences in HRQL between patients with or without acute GvHD. However, patients with extensive chronic GvHD reported impaired physical function compared to patients with limited chronic GvHD and those with no chronic GvHD at the 11/2-year follow-up (69 vs. 93 and 88, $\mathrm{P}<0.01$ ), at the 2 -year follow-up (76 vs. 92 and 94, $\mathrm{P}<0.01$ ) and at the $21 / 2$-year follow-up after HSCT (66 vs. 91 and $96, \mathrm{P}<0.01)$. They reported a highly affected role function after HSCT compared to patients with limited chronic GvHD at the 1 -year follow-up (36 vs. $72, \mathrm{P}<0.01)$, at the 11/2-year follow-up (39 vs. 77, $\mathrm{P}<0.01)$ and at the 2 -year follow-up $(49$ vs. $83, \mathrm{P}<0.01$ ). They also experienced an affected role function at the 1 -year follow-up (36 vs. $74, \mathrm{P}<0.01$ ), and at the $2 \frac{1}{2-}-$ year follow-up (44 vs. 86, P < 0.01), compared to the patients without chronic GvHD. Patients with chronic GvHD had a significantly worse overall QoL from month 6 after HSCT to the 11/2- year follow-up as compared to those with no or limited chronic GvHD $(\mathrm{P}<0.01)$, as shown in Figure 5.

\section{DISCUSSION}

The present prospective study on HRQL after allogeneic HSCT, with frequent evaluations covering the entire inpatient period and up to 3 years afterwards provides unique data on how HRQL parameters in the study population changed over time following allogeneic HSCT. Patients experienced a significant worsening of most functions and symptoms from baseline to weeks 2 or 3. Thereafter, there was a gradual improvement in their HRQL. Recovery after transplantation, which we view as a return to the baseline value, reached baseline at month 6 indicating that role function recovers quite rapidly. Almost all other assessment items had returned to the baseline value approximately $1-1 \frac{1}{2}$ years after the HSCT and remained stable thereafter. Similar results were found also when data from the 38 patients who survived and participated over the entire study period were separately analysed. Our results are consistent with those of other studies showing that it takes approximately 1 year after HSCT for patients to recover to the same level as before HSCT (Hjermstad et al. 2004; Grulke et al. 2012). At baseline, our results were fairly consistent with those of Grulke and co-workers' meta-analysis of 33 studies made in European countries, except for role function; which the patients in our study rated lower (45 vs. 62; Grulke et al. 2012). In Fayers et al. (2001) study, they suggest that there might be health and cultural differences between countries (Fayers 2001). Therefore, a possible explanation for the differences in role functioning could be unidentified cultural differences between Sweden and other European countries. Some of the decreased physical function during the inpatient period is probably due to a temporarily limited ability to perform physical activities, rather than any inherent inability to be physically active. At the 3-month assessment, the patients still rated their physical capacity as diminished, indicating that for most patients it takes at least this much time to recover after transplantation. Previous studies have shown that physical activities during and after HSCT have beneficial effects on patients' HRQL (Defor et al. 2007; Jarden et al. 2009; Baumann et al. 2010). Therefore, it is important for physiotherapists and nursing staff to find activities that encourage physical activity despite hospitalisation and isolation. For instance, virtual computer games can be used to increase the level of physical activity level during the inpatient period. This form of activity has been used in the rehabilitation of patients with stroke and could also be suitable for patients undergoing allogeneic HSCT (Lewis et al. 2011). Role function was the only function that improved significantly during the 3 years after HSCT. Similar results were also reported in a study on patients undergoing autologous HSCT (Frodin et al. 2011), and in a meta-analysis by Grulke et al. (2012). In their study, Syrjala et al. (2004) found that $33 \%$ of patients with a history of work outside the home had returned to full-time work after 3 years. This indicates that the majority of patients will only return to their normal lives after HSCT over a period of years, and also indicates that some patients will never return to a regular job. The symptoms mostly affected during the inpatient period were appetite loss, nausea, vomiting, and fatigue, followed by diarrhoea, sleep disturbance and pain. These results correspond well with the clinical picture of the toxicity of the given treatment. Our results are comparable with the results from the metaanalysis by Grulke et al. (2012), and results reported by Bevans et al. (2008). In our study, many of the patients experienced appetite loss, fatigue, dyspnoea and diarrhoea up to 6 months after HSCT. These symptoms could be due to several factors, such as gastrointestinal GvHD, infection, depression and malnutrition (Mattson 2007; Martin-Salces et al. 2008). These symptoms can lead to severe weight loss, which can be devastating for the patient's recovery. It is therefore important to monitor diet and eating habits after discharge. Approximately, half of the patients in our study were affected by acute or chronic GvHD. Of those, 25\% died due to GvHD. Patients who had extensive chronic GvHD had significantly impaired physical and role function and global QoL compared to those who had no or limited chronic GvHD. This result is consistent with results from other studies and points to the importance of providing appropriate support for patients affected by extensive chronic GvHD and implementing actions that increase their HRQL (Lee et al. 2006; Pallua et al. 2010; Pidala et al. 2011). This support might entail providing information about the benefits of self-care to reduce the problems of chronic GvHD, such as increased physical activity to prevent stiffening joints, which can be common in chronic GvHD (Chen 2014). The original reason for introducing RIC as an alternative to MAC was to reduce acute toxicity, while at the same time sustaining tumour control, safe engraftment and early full donor chimerism (Juliusson et al. 2003). Our RIC regimen thus included a relatively high dose of melphalan, and was more intense than many other RIC regimens, but still within the limits specified by Bacigalupo et al. (2009). The mean age of our RIC patients was similar to several other RIC studies, ranging between 45 and 52 years (Diez-Campelo et al. 2004; Bevans et al. 2006; Andersson et al. 2009; Cohen et al. 2012). In our centre, $46 \%$ of all AML patients aged between 40 and 59 years went through allogeneic HSCT as compared to $22 \%$ at other centres in Sweden, resulting in an improved 55\% long-term survival of all AML patients in this age group (Juliusson et al. 
2012). To the best of our knowledge, there are only five earlier studies that investigated HRQL in patients treated with RIC (Diez-Campelo et al. 2004; Bevans et al. 2006; Andersson et al. 2009, 2010; Cohen et al. 2012). Bevans et al. (2006) compared HRQL with SF-36, FACT-G and BMT in patients undergoing allogeneic HSCT with RIC or MAC regimes during the first 100 days after transplantation. They analysed data using mixed linear modelling, adjusting for baseline HRQL differences. HRQL was significantly improved $(<0.01)$ in both groups with higher scores at day 100 compared to days 0 and 30. There was no difference between groups during early recovery. At 2 years, all survivors reported HRQL similar to or better than at baseline (Bevans et al. 2006). Andersson et al. (2009) also compared patients going through allogeneic HSCT with RIC and MAC regimes. HRQL was measured using EORTC QLQ C-30 and module high-dose chemotherapy (HDC19). They found no difference between the two groups at baseline, whereas at 1 month after HSCT, MAC patients had significantly more sleep disturbances, financial problems, and mouth and taste problems. At the 1-year followup, patients who received MAC still had problems with dry mouth (Andersson et al. 2009). Our results differ from Bevans et al. (2006) and Andersson et al. (2009) since our patients treated with MAC had significantly more fatigue and nausea and vomiting even at baseline compared to patients treated with RIC. A possible explanation for the difference at baseline is that some MAC patients in this group had more limited time than RIC patients to recover from previous chemotherapy before the transplantation. However, due to the small study population in our MAC group the result must be interpreted with caution. At weeks 3 and 4, the patients treated with MAC also reported significantly more pain, sleep disturbances, loss of appetite and diarrhoea than the RIC patients. Pain during the early phase of our study was probably due to mucositis, which is a common side effect after MAC, but it also affects some patients treated with RIC (Ohbayashi et al. 2008; Takahashi et al. 2010). When performing studies on vulnerable patients, ethical considerations are crucial. The patients in our study were asked to fill out the questionnaire, even at times when clinical experience indicated that they could feel most negatively affected depending on the acute toxicity after conditioning. This could be regarded as troublesome for the patient, but any negative effects are probably outweighed by the patients' interest in reporting their symptoms. Since the researcher (UF) has taken an active part in the distribution and collection of the questionnaires, there is a risk that the patients had an emotional relationship with the researcher. The advantage of the researcher distributing the questionnaires is that the response rate is probably higher. The researcher (UF) has not had an active part in the daily care of the patients in the study. Since the study started, no patients have discontinued participation due to the questions being too offensive or too difficult to answer.

The strength of this study is the use of frequent and regular follow-ups during both the inpatient period and the 3-year follow-up which provide valid data illustrating fluctuations in patients' HRQL, giving a good overall clinical picture of how the patients felt during and after allogeneic HSCT, and strengthens the validity and transferability of the results.

\section{LIMITATION}

A limitation of our study is the $60 \%$ decrease of our study population from baseline until the 3-year follow-up, leaving a study population of 38 patients at the end of the study. The most common reason for not remaining in the study was death (47\%), followed by relapse (30\%), infections (32\%) and GvHD (25\%). This distribution reflects the fact that many patients had HSCT for advanced disease with a high risk of complications. Patients who died had reported values indicating greater impairment in some variables at baseline compared to patients who survived, demonstrating that the patients who died were already in worse general condition before HSCT than the patients who survived. To further validate our results, we made an analysis of the 34 surviving patients who answered all the questionnaires throughout the study period. This analysis showed that HRQL followed the same pattern among the survivors as the total study population. This further strengthens our results. The high mortality rates during the study were unfortunately unavoidable and emphasise the high risk involved with allogeneic HSCT. Our data are comparable with data in a study by Bhatia et al. (2007), who studied late mortality after HSCT. They found that relapse, chronic GvHD and infection were the primary reasons for death (Bhatia et al. 2007). A retrospective analysis using data from the EBMT database shows that $46 \%$ of patients transplanted with an allogeneic HSCT between 1990 and 2005 died; of these, 28\% died from transplant-related causes (Gratwohl et al. 2009). This illustrates the challenge of conducting longitudinal studies in patients with severe diseases and poor survival. In the result section, we chose to report statistically significant differences; it may also be appropriate to take non-statistically significant differences into account in guiding clinical practice. In other words, small changes in HRQL that are not statistically significant must be considered as being of possible importance for individual patients (Polit \& Beck 2008). Statistical significance is partly dependent on the size of the study population and related to the validity of the result, whereas non-significant differences could also suggest clinically significant findings. It has been recommended that a change in mean value of 10 points or more in the score should be defined as clinically significant, irrespective of the P-value (King 1996; Osoba et al. 1998; Maringwa et al. 2011). A limitation in our methodological approach is that the EORTC QLQ C-30 provides general knowledge of the patients' HRQL, but not a deeper understanding of the different aspects of the patients HRQL. For instance, patients are asked to answer whether they have diarrhoea. The response alternatives are not at all, a little, quite a bit and very much. This is a subjective evaluation about the patients' symptoms and can be interpreted in several ways; either the frequency or the amount of diarrhoea. However, it does not say anything about the distress that the symptom may cause. It would have been an advantage to also use instruments that explore in depth the areas more specific for patients going through HSCT such as 'the module High-Dose Chemotherapy (HDC 19)'. This module is directed to patients undergoing HSCT (Andersson et al. 2008), but was not available when we started the study.

\section{Conclusion}

It took at least 1 year for the patients' HRQL to return to the baseline level. The only function that had improved significantly 3 years after HSCT was role function. This is important information since it indicates the stages in the treatment period when the patient needs more support and illustrate the need for early and supportive intervention, particularly for appetite loss and chronic GvHD. Week 2 and 3 is the period in which patients undergoing allogeneic HSCT need the most supportive care. 
The patients with MAC regimens experienced a worse HRQL at baseline than the patients with RIC regimens, and subsequently more pain, sleep disturbance and appetite loss in weeks 3 and 4. Although our patients treated with MAC s experienced worse HRQL, HSCT with RIC still had a great impact on HRQL, especially during the first year after HSCT. Patients with extensive chronic GvH experienced reduced HRQL.

\section{Clinical implications}

Based on the results of the study, there are several clinical implications. First, we recommend that healthcare professionals perform close follow-ups, using standardized assessment scales covering the most troublesome and frequent symptoms or impairments. Exercise programmes or virtual computer games could be used to increase patients' physical function during and after transplantation. Increased support during hospitalisation can provide faster recovery and may reduce the number of hospital days. The results will also help the healthcare personnel to inform patients and help the patients to understand what they have to expect during and after the transplantation, and that the recovery after the transplantation takes time for patients undergoing allogeneic HSCT. Since patients undergoing allogeneic HSCT have a severe disease with poor survival future, multicentre studies are recommended that will be able to reach adequate power. There is also a need for further prospective studies on HRQL focusing on the inpatient period in patients treated with RIC and also a need for studies investigating interventions for the most troublesome symptoms.

\section{FUNDING}

This study was financially supported by the County Council of Östergötland and the Blood Cancer Fund in Sweden.

\section{REFERENCES}

Aaronson N.K. (1993) The European Organization for Reseaech and Treatment of Cancer QLQ-C30: A Quality-of-life instrument for use in interantional clinical trials in oncology. Journal of the National Cancer Institute 5, 365-376.

Andersson I., Hjermstad M., Stockelberg D. \& Persson L.O. (2008) Health related quality of life in stem cell transplantation: clinical and psychometric validation of the questionnaire module, High Dose Chemotherapy (HDC-19). Acta Oncologica 47, $275-285$.

Andersson I., Ahlberg K., Stockelberg D., Brune M. \& Persson L.O. (2009) Healthrelated quality of life in patients undergoing allogeneic stem cell transplantation after reduced intensity conditioning versus myeloablative conditioning. Cancer Nursing 32, 325-334.

Andersson I., Ahlberg K., Stockelberg D. \& Persson L.O. (2010) Patients' perception of health-related quality of life during the first year after autologous and allogeneic stem cell transplantation. European Journal of Cancer Care (England) 20, 368-379.

Apperley J. \& Masszi T. (2012) Graft-versus- host disease. In: The EBMT Handbook Haematopoetic Stem Cell Transplantation (eds Apperley J., Carreras E., Gluckman E. \& Masszi T.), pp. 216-233. Litoprint, Paris, France.

Bacigalupo A., Ballen K., Rizzo D., Giralt S., Lazarus H., Ho V., Apperley J., Slavin S., Pasquini M., Sandmaier B.M., Barrett J., Blaise D., Lowski R. \& Horowitz M. (2009) Defining the intensity of conditioning regimens: working definitions. Biology of Blood and Marrow Transplantation 15, 1628- 1633 .

Baumann F.T., Kraut L., Schule K., Bloch W. \& Fauser A.A. (2010) A controlled randomized study examining the effects of exercise therapy on patients undergoing haematopoietic stem cell transplantation. Bone Marrow Transplantation 45, 355-362.

Bevans M.F., Marden S., Leidy N.K., Soeken K., Cusack G., Rivera P., Mayberry H., Bishop M.R., Childs R. \& Barrett A.J. (2006) Healthrelated quality of life in patients receiving reducedintensity conditioning allogeneic hematopoietic stem cell transplantation. Bone Marrow Transplantation 38, 101- 109.

Bevans M.F., Mitchell S.A. \& Marden S. (2008) The symptom experience in the first 100 days following allogeneic hematopoietic stem cell transplantation (HSCT). Supportive Care in Cancer 16, 1243-1254.

Bhatia S., Francisco L., Carter A., Sun C.L., Baker K.S., Gurney J.G., Mcglave P.B., Nademanee A., O’donnell M., Ramsay N.K., Robison L.L., Snyder D., Stein A., Forman S.J. \& Weisdorf D.J. (2007) Late mortality after allogeneic hematopoietic cell transplantation and functional status of long-term survivors: report from the Bone Marrow Transplant Survivor Study. Blood 110, 3784-3792.

Braamse A.M., Gerrits M.M., Van Meijel B., Visser O., Van Oppen P., Boenink A.D., Cuijpers P., Huijgens P.C., Beekman A.T. \& Dekker J. (2012) Predictors of health-related quality of life in patients treated with auto- and allo-SCT for hematological malignancies. Bone Marrow Transplantation 47, 757-769.

Chen Y.-B. (2014) Graft-versus-host disease. Available at: http:// www.nlm.nih.gov/medlineplus/ency/ article/001309.htm (accessed 1 February 2015).

Cohen M.Z., Rozmus C.L., Mendoza T.R., Padhye N.S., Neumann J., Gning I., Aleman A., Giralt S. \& Cleeland C.S. (2012) Symptoms and quality of life in diverse patients undergoing hematopoietic stem cell transplantation. Journal of Pain and Symptom Management 44, 168180 .

Cremer B., Sandmaier B.M., Bethge W., Lange T., Goede V., Holtick U., Hallek M. \& Hubel K. (2011) Reduced-intensity conditioning in allogeneic stem cell transplantation for hematological malignancies: a historical perspective. Onkologie 34, 710-715.

Decker W.A., Turner-Mcglade J. \& Fehir K.M. (1989) Psychosocial aspects and the physiological effects of a cardiopulmonary exercise program in patients undergoing bone marrow transplantation (BMT) for acute leukemia (AL). Transplantation Proceedings 21, $3068-3069$. 
Defor T.E., Burns L.J., Gold E.M. \& Weisdorf D.J. (2007) A randomized trial of the effect of a walking regimen on the functional status of 100 adult allogeneic donor hematopoietic cell transplant patients. Biology of Blood and Marrow Transplantation 13, $948-955$.

Diaconescu R., Flowers C.R., Storer B., Sorror M.L., Maris M.B., Maloney D.G., Sandmaier B.M. \& Storb R. (2004) Morbidity and mortality with nonmyeloablative compared with myeloablative conditioning before hematopoietic cell transplantation from HLA-matched related donors. Blood 104, 1550-1558.

Diez-Campelo M., Perez-Simon J.A., Gonzalez-Porras J.R., Garcia-Cecilia J.M., Salinero M., Caballero M.D., Canizo M.C., Ocio E.M. \& Miguel J.F. (2004) Quality of life assessment in patients undergoing reduced intensity conditioning allogeneic as compared to autologous transplantation: results of a prospective study. Bone Marrow Transplantation, 729-738.

Fayers P.M. (2001) Interpreting quality of life data: population-based reference data for the EORTC QLQ-C30. European Journal of Cancer 37, 1331- 1334

Fayers PM., Aaronson NK., Bjordal K., Groenvold M., Curran D., Bottomley A., on behalf of the EORTC Quality of Life Group. The EORTC QLQ-C30 Scoring Manual (3rd Edition). Published by: European Organisation for Research and Treatment of Cancer Brussels 2001.

Frodin U., Borjeson S., Lyth J. \& Lotfi K. (2011) A prospective evaluation of patients' health-related quality of life during auto-SCT: a 3 year follow-up. Bone Marrow Transplantation 46, 1345- 1352.

Gratwohl A., Carreras E. (2012) Principles of conditioning. In: The EBMT Handbook-Haematopoetic Stem Cell Transplantation, 6th edn (eds Apperley J.C..E., Gluckman E. \& Masszi T.), pp. 122-137. ESH, Paris, France.

Gratwohl A., Stern M., Brand R., Apperley J., Baldomero H., De Witte T., Dini G., Rocha V., Passweg J., Sureda A., Tichelli A. \& Niederwieser D. (2009) Risk score for outcome after allogeneic hematopoietic stem cell transplantation: a retrospective analysis. Cancer $115,4715-4726$

Grulke N., Albani C. \& Bailer H. (2012) Quality of life in patients before and after haematopoietic stem cell transplantation measured with the European Organization for Research and Treatment of Cancer (EORTC) Quality of Life Core Questionnaire QLQ-C30. Bone Marrow Transplantation 47, 473-482.

Gyurkocza B. \& Sandmaier B.M. (2014) Conditioning regimens for hematopoietic cell transplantation: one size does not fit all. Blood 124, 344-353.

Hjermstad M.J., Fayers P.M., Bjordal K. \& Kaasa S. (1998) Using reference data on quality of life-the importance of adjusting for age and gender, exemplified by the EORTC QLQ-C30 (+3). European Journal of Cancer 34, 1381-1389.

Hjermstad M.J., Knobel H., Brinch L., Fayers P.M., Loge J.H., Holte H. \& Kaasa S. (2004) A prospective study of health-related quality of life, fatigue, anxiety and depression 3-5 years after stem cell transplantation. Bone Marrow Transplantation 34, 257-266.

Jarden M., Baadsgaard M.T., Hovgaard D.J., Boesen E. \& Adamsen L. (2009) A randomized trial on the effect of a multimodal intervention on physical capacity, functional performance and quality of life in adult patients undergoing allogeneic SCT. Bone Marrow Transplantation 43, 725-737.

Juliusson G., Karlsson K., Malm C., Frodin U., Mollen A.S., Backstrom G. \& Soderkvist P. (2003) Adjusted conditioning for allogeneic transplantation in a single center setting: mixed chimerism heralds relapse. Leukaemia and Lymphoma 44, 669-679.

Juliusson G., Theorin N., Karlsson K., Frodin U. \& Malm C. (2006) Subcutaneous alemtuzumab vs ATG in adjusted conditioning for allogeneic transplantation: influence of Campath dose on lymphoid recovery, mixed chimerism and survival. Bone Marrow Transplantation 37, 503-510.

Juliusson G., Lazarevic V., Horstedt A.S., Hagberg O. \& Hoglund M. \& Swedish Acute Leukemia Registry Group (2012) Acute myeloid leukemia in the real world: why population-based registries are needed. Blood 119, 3890-3899.

King M.T. (1996) The interpretation of scores from the EORTC quality of life questionnaire QLQ-C30. Quality of Life Research 5, $555-567$.

Larsen J., Nordstrom G., Ljungman P. \& Gardulf A. (2004) Symptom occurrence, symptom intensity, and symptom distress in patients undergoing highdose chemotherapy with stem-cell transplantation. Cancer Nursing 27, 55- 64.

Larson P.J., Viele C.S., Coleman S., Dibble S.L. \& Cebulski C. (1993) Comparison of perceived symptoms of patients undergoing bone marrow transplant and the nurses caring for them. Oncology Nursing Forum 20, 81-87; discussion 87-88.

Lee S.J., Kim H.T., Ho V.T., Cutler C., Alyea E.P., Soiffer R.J. \& Antin J.H. (2006) Quality of life associated with acute and chronic graftversus-host disease. Bone Marrow Transplantation 38, 305-310.

Lewis G.N., Woods C., Rosie J.A. \& Mcpherson K.M. (2011) Virtual reality games for rehabilitation of people with stroke: perspectives from the users. Disability and Rehabilitation. Assistive Technology 6, 453-463.

Ljungman P., Bregni M., Brune M., Cornelissen J., De Witte T., Dini G., Einsele H., Gaspar H.B., Gratwohl A., Passweg J., Peters C., Rocha V., Saccardi R., Schouten H., Sureda A., Tichelli A., Velardi A. \& Niederwieser D. (2010) Allogeneic and autologous transplantation for haematological diseases, solid tumours and immune disorders: current practice in Europe 2009. Bone Marrow Transplantation 45, 219-234 
C.S., Flechtner H., Gotay C., Greimel E., Taphoorn M.J., Reeve B.B., Koch J.S., Weis J., Smit E.F., Van Meerbeeck J.P. \& Bottomley A. (2011) Minimal important differences for interpreting healthrelated quality of life scores from the EORTC QLQ-C30 in lung cancer patients participating in randomized controlled trials. Supportive Care in Cancer 19, 1753-1760.

Martin-Salces M., De Paz R., Canales M.A., Mesejo A. \& Hernandez-Navarro F. (2008) Nutritional recommendations in hematopoietic stem cell transplantation. Nutrition 24, 769-775.

Mattson M.R. (2007) Graft-versus-host disease: review and nursing implications. Clinical Journal of Oncology Nursing 11, 325-328.

Mcquellon R.P., Russell G.B., Cella D.F., Craven B.L., Brady M., Bonomi A. \& Hurd D.D. (1997) Quality of life measurement in bone marrow transplantation: development of the Functional Assessment of Cancer Therapy-Bone Marrow Transplant (FACT-BMT) scale. Bone Marrow Transplantation 19, 357-368.

Mcquellon R.P., Russell G.B., Rambo T.D., Craven B.L., Radford J., Perry J.J., Cruz J. \& Hurd D.D. (1998) Quality of life and psychological distress of bone marrow transplant recipients: the 'time trajectory' to recovery over the first year. Bone Marrow Transplantation 21, 477-486.

Ohbayashi Y., Imataki O., Ohnishi H., Iwasaki A., Ogawa T., Inagaki N., Shigeta H., Ohue Y., Tasaka T., Kitanaka A., Kubota Y., Tanaka T., Ishida T. \& Miyake M. (2008) Multivariate analysis of factors influencing oral mucositis in allogeneic hematopoietic stem cell transplantation. Annals of Hematology 87, 837-845.

Osoba D., Rodrigues G., Myles J., Zee B. \& Pater J. (1998) Interpreting the significance of changes in health-related quality-of-life scores. Journal of Clinical Oncology 16, 139-144.

Pallua S., Giesinger J., Oberguggenberger A., Kemmler G., Nachbaur D., Clausen J., Kopp M., Sperner-Unterweger B. \& Holzner B. (2010) Impact of GvHD on quality of life in long-term survivors of haematopoietic transplantation. Bone Marrow Transplantation 45, 1534-1539.

Pidala J., Kurland B., Chai X., Majhail N., Weisdorf D.J., Pavletic S., Cutler C., Jacobsohn D., Palmer J., Arai S., Jagasia

M. \& Lee S.J. (2011) Patient-reported quality of life is associated with severity of chronic graft-versus-host disease as measured by NIH criteria: report on baseline data from the Chronic GVHD Consortium. Blood 117, 4651-4657.

Polit D.F. \& Beck C.T. (2008) Nursing Research, Generating and Assessing Evidence for Nursing Practice, 8th edn. Lippincott Williams \& Wilkins, Philadelphia, USA.

Socie G., Salooja N., Cohen A., Rovelli A., Carreras E., Locasciulli A., Korthof E., Weis J., Levy V. \& Tichelli A. (2003) Nonmalignant late effects after allogeneic stem cell transplantation. Blood 101, 3373-3385.

Syrjala K.L., Langer S.L., Abrams J.R., Storer B., Sanders J.E., Flowers M.E. \& Martin P.J. (2004) Recovery and longterm function after hematopoietic cell transplantation for leukemia or lymphoma. JAMA 291, 2335-2343.

Takahashi K., Soga Y., Murayama Y., Udagawa M., Nishimoto H., Sugiura Y., Maeda Y., Tanimoto M. \& Takashiba S. (2010) Oral mucositis in patients receiving reduced-intensity regimens for allogeneic hematopoietic cell transplantation: comparison with conventional regimen. Supportive Care in Cancer 18, 115-119

Zittoun R., Achard S. \& Ruszniewski M. (1999) Assessment of quality of life during intensive chemotherapy or bone marrow transplantation. Psychooncology 8, 64-73. 
Table 1. Patient characteristics

Number of patients (n)

Men/Women (n, \%)

Age, mean (median)

94

MAC/RIC

$47 / 47(50 / 50)$

48

Marital status (n, \%)

Married/Cohabiting/Partner $\quad 72(77)$

$22(23)$

Stem cell source (n, \%)

Peripheral blood haematopoietic cells $85(90)$

Bone marrow 7 (8)

Cord blood $2(2)$

Donor: RD/URD (n, \%) 42/52 (45/55)

Conditioning regimens $(\mathrm{n}, \%)$

$\mathrm{MAC}^{*} / \mathrm{RIC}+$

$16 / 78(17 / 83)$

Serotherapy (n, \%)

Alemtuzumab/Antithymoglobulin (n) 71/17 (76/18)

Inpatient period, mean (range)

Days of hospitalisation

$32(18-162)$

MAC/RIC

Days with neutrophil counts $<0.5$

MAC/RIC 20 (10-54)/16(11-31)

Diagnosis (baseline/at 3 years) $\mathrm{N}$

Acute leukaemia 51/22

Myelodysplastic syndrome 8/1

Chronic myeloid leukaemia 7/4

Chronic lymphocytic leukaemia 4/3

Myeloproliferative disease 4/1

Multiple myeloma 10/2

Lymphoma 5/2

Prolymphocytic leukaemia $1 / 0$

Othert 4/3

Acute GvHD (n)

Grade 1 and 2/Grade 3 and 437/17

Chronic GVHD (n)

Limited/Extensive 19/31 


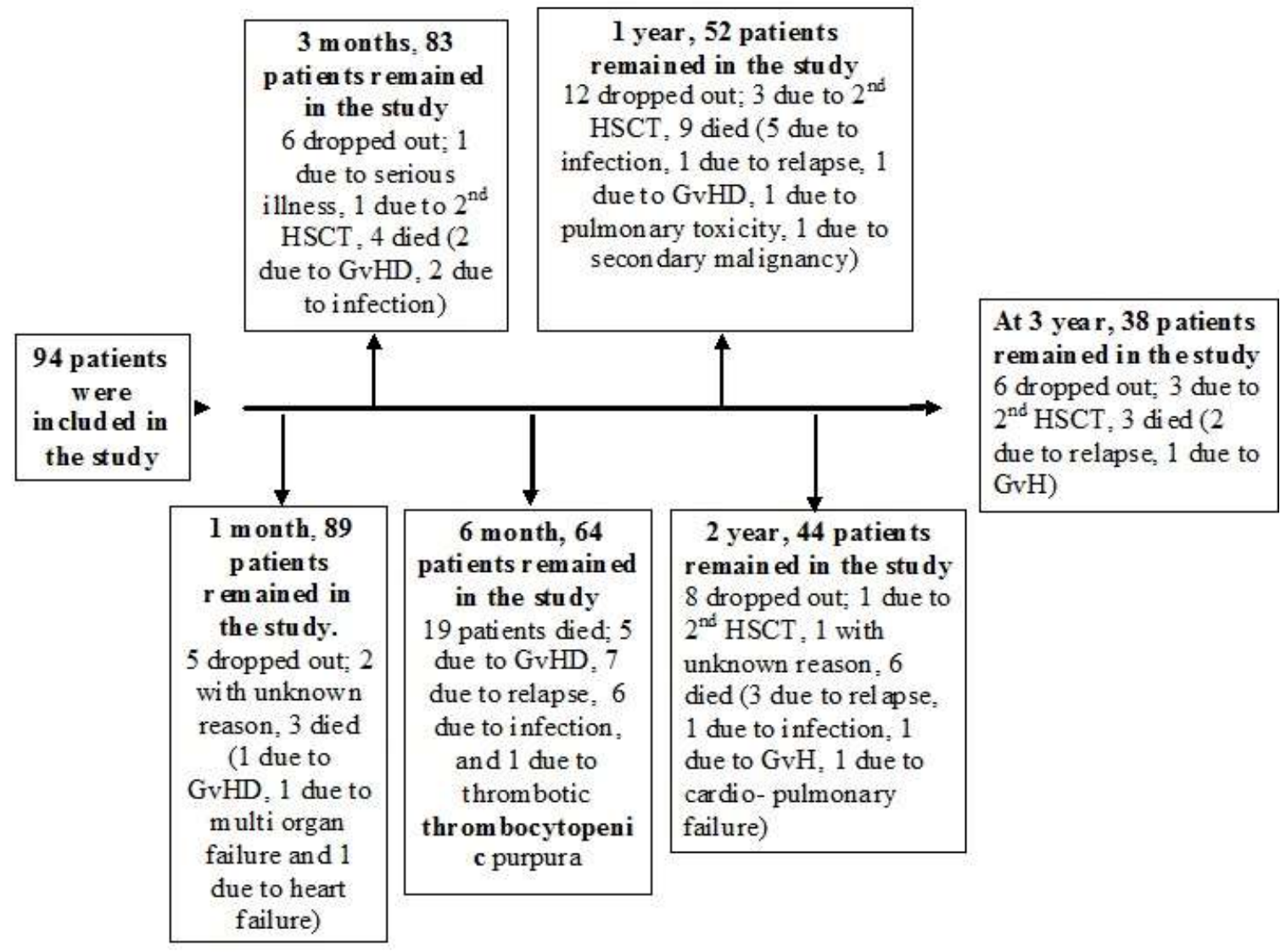

Fig. 1.

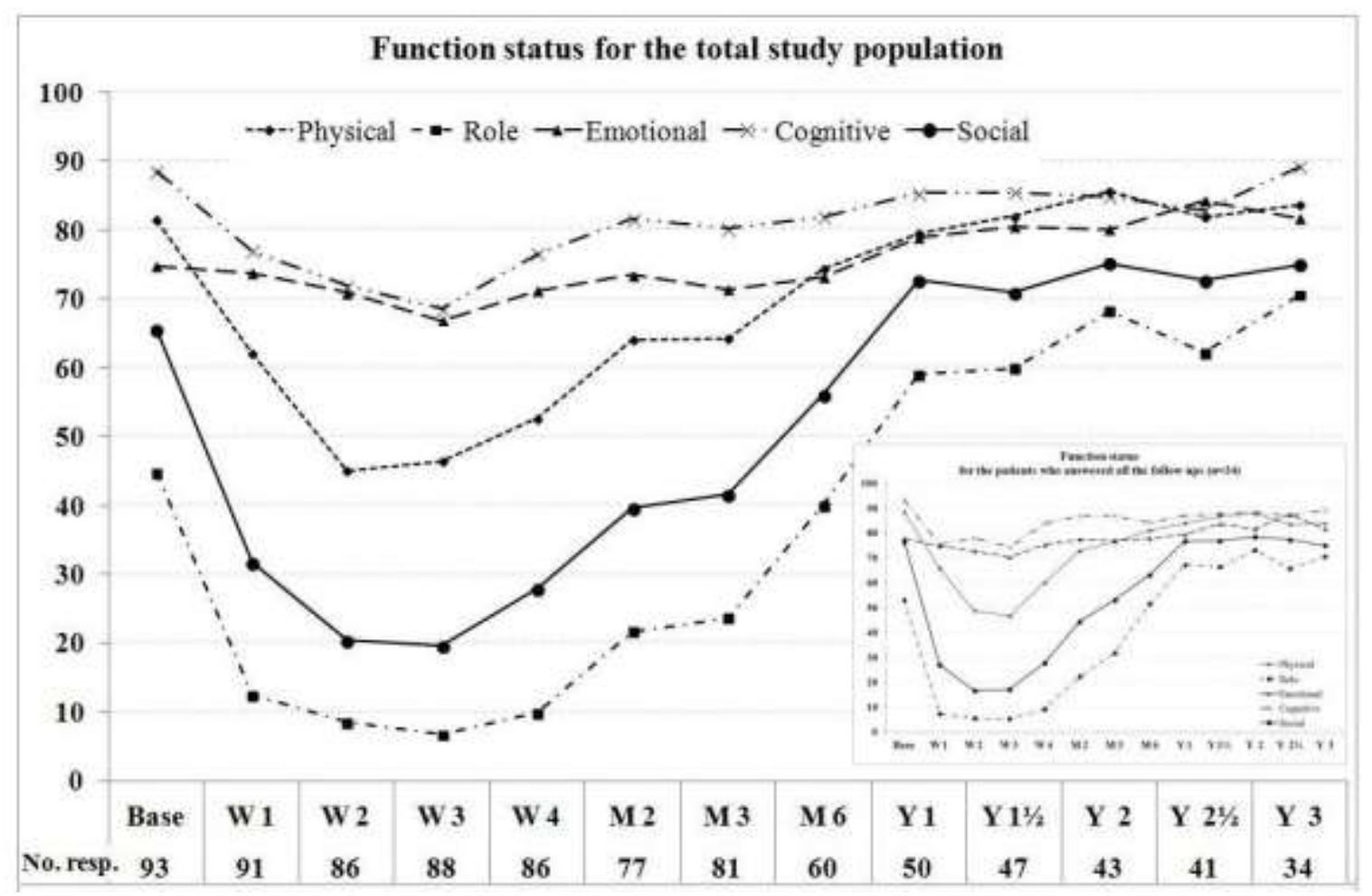

Fig. 2 


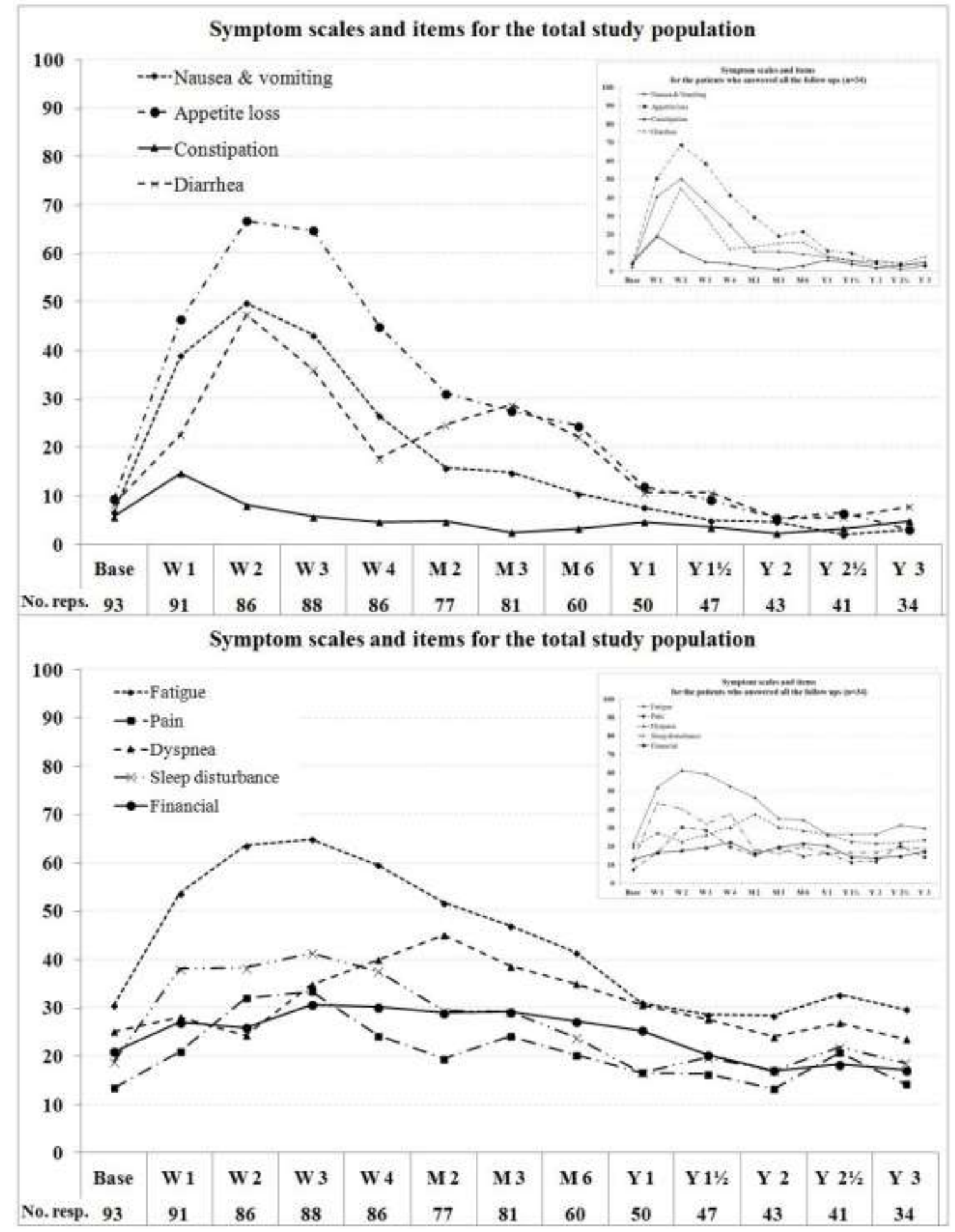

Fig. 3 . 


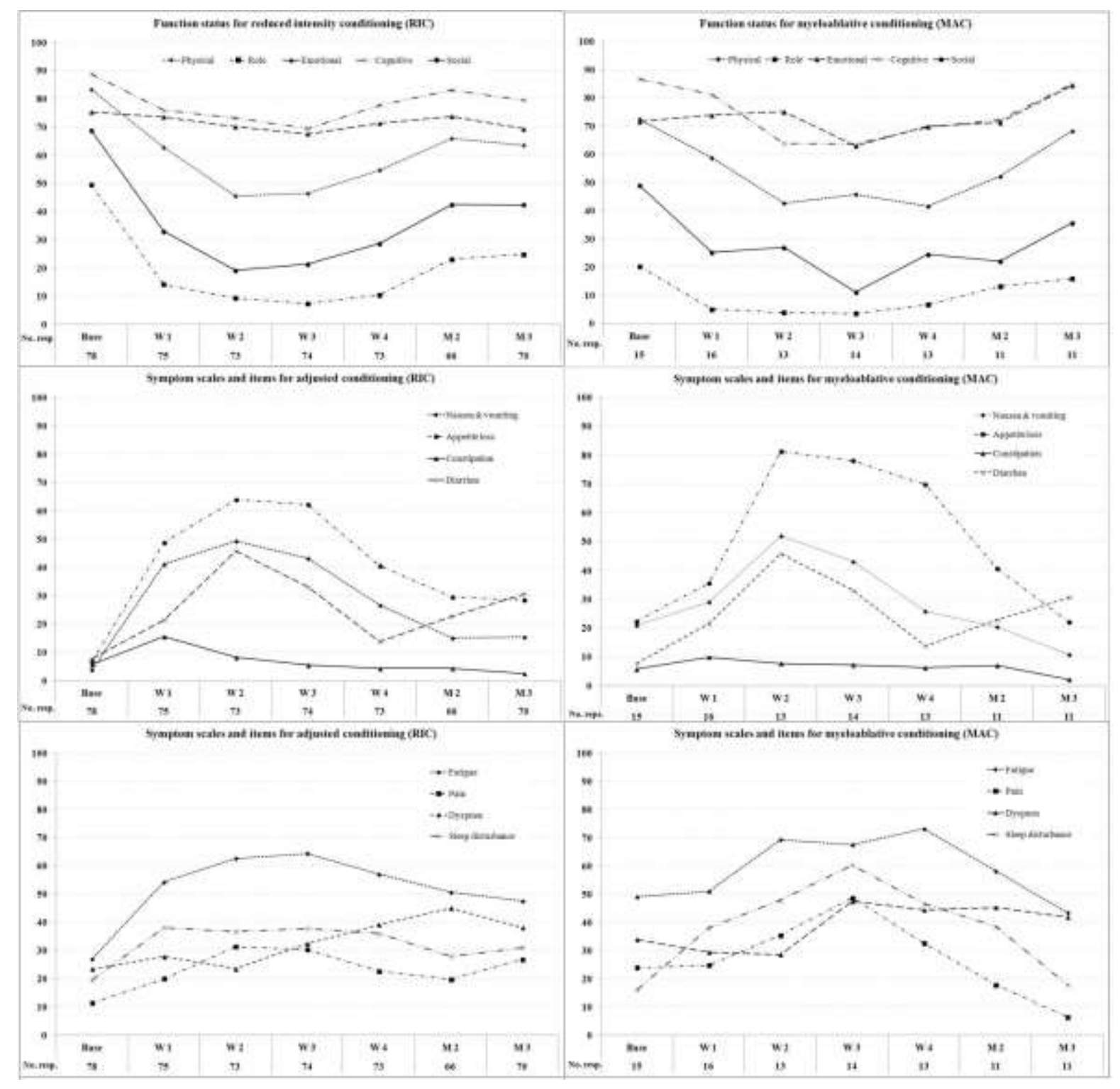

Fig. 4. 
Global health status/Quality of life

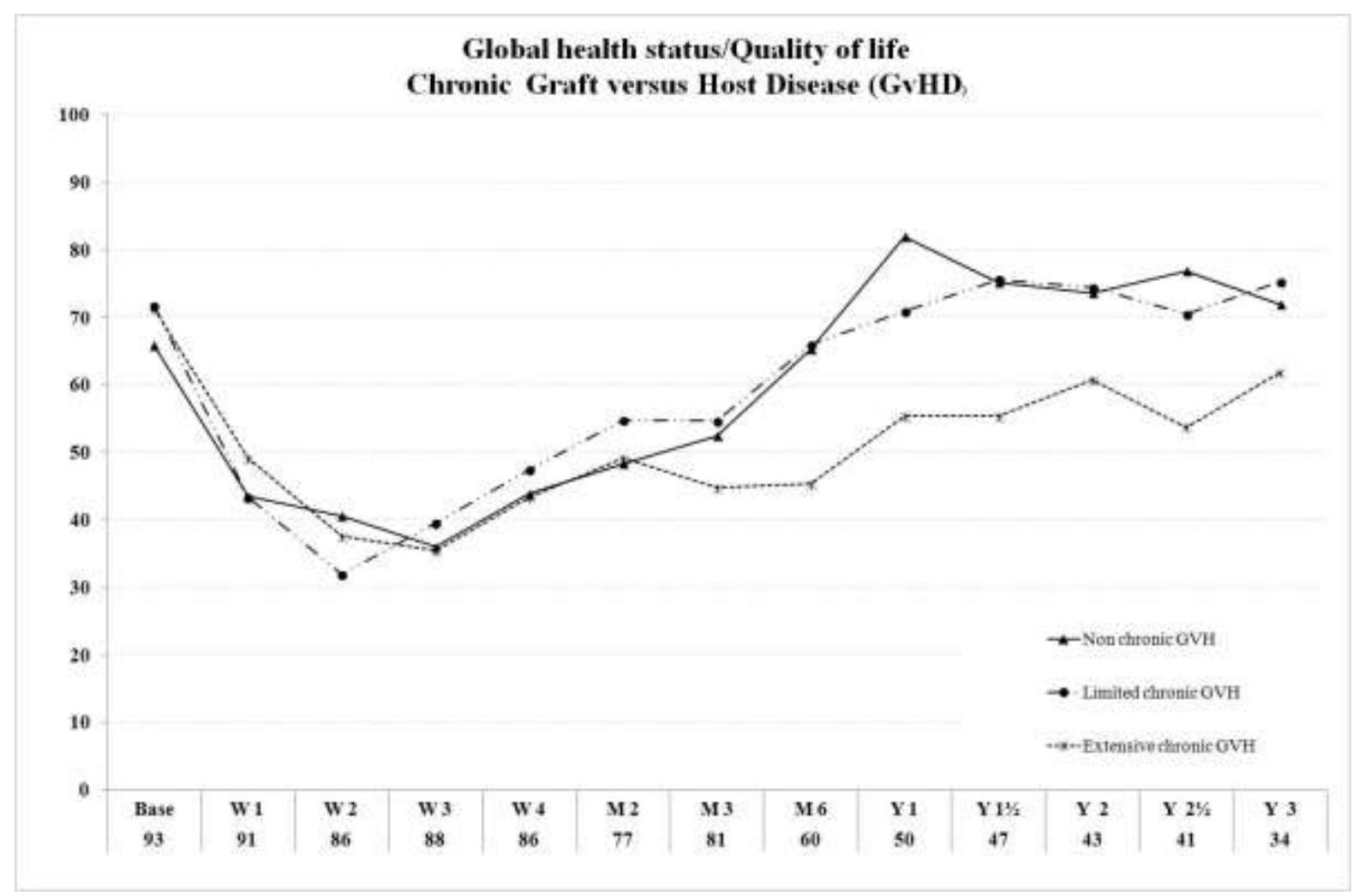

Fig. 5. 
Table 1. Patient characteristics

\begin{tabular}{|c|c|}
\hline $\begin{array}{l}\text { Number of patients } \\
\text { (n) }\end{array}$ & 94 \\
\hline Men/Women (n) (\%) & $47 / 47(50 / 50)$ \\
\hline $\begin{array}{l}\text { Age, mean(median) } \\
\text { MAC/RIC }\end{array}$ & $\begin{array}{l}48 \\
40 / 49(41 / 53)\end{array}$ \\
\hline $\begin{array}{l}\text { Marital status (n) }(\%) \\
\text { Married/Cohabiting/Partner } \\
\text { Single }\end{array}$ & $\begin{array}{l}72(77) \\
22(23)\end{array}$ \\
\hline $\begin{array}{l}\text { Stem cell source }(\mathrm{n})(\%) \\
\text { Peripheral blood hematopoietic cells } \\
\text { Bone Marrow } \\
\text { Cord blood }\end{array}$ & $\begin{array}{l}85(90) \\
7(8) \\
2(2)\end{array}$ \\
\hline Donor: $\mathrm{RD}^{1} / \mathrm{URD}^{2}(\mathrm{n})(\%)$ & $42 / 52(45 / 55)$ \\
\hline $\begin{array}{l}\text { Conditioning regimens (n) (\%) } \\
\mathrm{MAC}^{3} / \mathrm{RIC}^{4}\end{array}$ & $16 / 78(17 / 83)$ \\
\hline $\begin{array}{l}\text { Serotherapy (n) (\%) } \\
\text { Alemtuzumab/Antithymoglobulin (n) }\end{array}$ & $71 / 17(76 / 18)$ \\
\hline $\begin{array}{l}\text { Inpatient period, mean (range) } \\
\text { Days of hospitalization, } \\
\text { MAC/RIC } \\
\text { Days with neutrophil counts }<0,5 \\
\text { MAC/RIC }\end{array}$ & $\begin{array}{l}32(18-162) \\
39(23-69) / 31(18-162) \\
16(10-54) \\
20(10-54) / 16(11-31)\end{array}$ \\
\hline $\begin{array}{l}\text { Diagnosis (baseline / at } 3 \text { years) } \\
\text { Acute leukemia } \\
\text { Myelodysplastic syndrome } \\
\text { Chronic myeloid leukemia } \\
\text { Chronic lymphocytic leukemia } \\
\text { Myeloproliferative disease } \\
\text { Multiple myeloma } \\
\text { Lymphoma } \\
\text { Prolymphocytic leukemia } \\
\text { Other }^{5}\end{array}$ & $\begin{array}{l}\text { Number } \\
51 / 22 \\
8 / 1 \\
7 / 4 \\
4 / 3 \\
4 / 1 \\
10 / 2 \\
5 / 2 \\
1 / 0 \\
4 / 3\end{array}$ \\
\hline $\begin{array}{l}\text { Acute GvHD } \mathbf{~}^{12}(\mathrm{n}) \\
\text { Grade } 1 \& 2 / \text { Grade } 3 \& 4\end{array}$ & $37 / 17$ \\
\hline $\begin{array}{l}\text { Chronic GVHD (n) } \\
\text { Limited/Extensive }\end{array}$ & $19 / 31$ \\
\hline
\end{tabular}

${ }^{1}$ RD: Related donor, ${ }^{2}$ URD: Unrelated donor

${ }^{3}$ Myeloablative conditioning (MAC): TBI+FAM (Total body irradiation: $12 \mathrm{~Gy}$, Fludarabine $50 \mathrm{mg} / \mathrm{day}$, and Ara-C $1 \mathrm{~g} / \mathrm{m}^{2}$ for three days; Melphalan $140 \mathrm{mg} / \mathrm{m}^{2}$ on day -1), BEAM (Becenun $300 \mathrm{mg} / \mathrm{m}^{2}$, and Etoposide $200 \mathrm{mg} / \mathrm{m}^{2}$, and Ara-C: $400 \mathrm{mg} / \mathrm{m}^{2}$ for four days; Melphalan: $140 \mathrm{mg} / \mathrm{m}^{2} \mathrm{on} \mathrm{day}-1$ ), BuCy (Busulphan $4 \mathrm{mg} / \mathrm{kg}$ for four days, Cyclophosphamide $60 \mathrm{mg} / \mathrm{kg}$ for two days), FLAMSA-Cy-TBI (Fludarabine $30 \mathrm{mg} / \mathrm{m}^{2}$, and Ara-C $2 \mathrm{~g} / \mathrm{m}^{2}$, and Amsacrin $100 \mathrm{mg} / \mathrm{m}^{2}$ for four days; Cyclophosphamide $40 \mathrm{mg} / \mathrm{kg}$ for two days; TBI 4Gy on day -4).

${ }^{4}$ Reduced intensity conditioning (RIC): FCM (Fludarabine $80 \mathrm{mg} /$ day, and Cyclophosphamide $300 \mathrm{mg} /$ day, both orally for five days; Melphalan 140 $\mathrm{mg} / \mathrm{m}^{2}$ intravenously on day -1), FC + ATG (Fludarabine $50 \mathrm{mg} / \mathrm{day}$, and Cyclophosphamide $500 \mathrm{mg} / \mathrm{m}^{2}$ for five days; antithymoglobulin: $4-8 \mathrm{mg} / \mathrm{kg}$ in 4 days), FAM (Fludarabine $50 \mathrm{mg} /$ day, and Ara-C $1 \mathrm{~g} / \mathrm{m}^{2}$ for five days; Melphalan $140 \mathrm{mg} / \mathrm{m}^{2}$ on day -1 ), IFAM, MFAM (I=Idarubicin $20 \mathrm{mg}, \mathrm{M=}$ Mitoxantrone $12 \mathrm{mg} / \mathrm{m}^{2}$ ), FluBu (Fludarabine $30 \mathrm{mg} / \mathrm{m}^{2}$ for six days, Busulphan $4 \mathrm{mg} / \mathrm{kg}$ for two days).

${ }^{5}$ Other: 2 aplastic anaemia and 2 paroxysmal nocturnal hemoglobinuria, ${ }^{6} \mathbf{G V H D}$ : Graft versus host disease, 
Table 2. Difference in health-related quality of life between baseline and follow -ups at week 3, year 1 and 3 over a 3-year period measured with EORTC QLQ C-30 (0 - 100 points)

\begin{tabular}{|c|c|c|c|c|c|}
\hline & \multirow{2}{*}{$\begin{array}{l}\text { Mean } \\
\text { Baseline }\end{array}$} & \multicolumn{4}{|c|}{ Diff with mean at baseline (n)a } \\
\hline & & Week 3 & Month 3 & Year 1 & Year 3 \\
\hline Quality of life & 69 & $-34(87) *$ & $-19(80) *$ & $-3(50)$ & $-8(34)$ \\
\hline Physical & 81 & $-36(79) *$ & $-20(80) *$ & $-8(50)$ & $-5(34)$ \\
\hline Role & 45 & $-39(84) *$ & $-24(79) *$ & $9(50)$ & $18(34) *$ \\
\hline Emotional & 75 & $-8(87) *$ & $-2(80)$ & $3(50)$ & $4(34)$ \\
\hline Cognitive & 89 & $-20(87) *$ & $-7(80) *$ & $-5(50)$ & $-4(34)$ \\
\hline Social & 66 & $-46(86) *$ & $-23(80) *$ & $7(50)$ & $-1(34)$ \\
\hline Fatigue & 31 & $36(87) *$ & $18(80) *$ & $6(50)$ & $8(34)$ \\
\hline Pain & 13 & $21(87) *$ & $12(80) *$ & $6(50)$ & $7(34)$ \\
\hline Dyspnea & 25 & $11(86) *$ & $14(80) *$ & $8(50)$ & $4(34)$ \\
\hline Sleep disturbance & 19 & $23(86) *$ & $11(80) *$ & $3(50)$ & $7(34)$ \\
\hline Nausea \& Vomiting & 7 & $38(87) *$ & $11(80) *$ & $5(50) *$ & $1(34)$ \\
\hline Appetite loss & 9 & $58(87) *$ & $21(80) *$ & $9(50) *$ & $-1(33)$ \\
\hline Constipation & 6 & $0(86)$ & $-3(80)$ & $0(50)$ & $0(34)$ \\
\hline Diarrhea & 8 & $29(85) *$ & $22(79) *$ & $5(49)$ & $3(33)$ \\
\hline
\end{tabular}

$\alpha$ The difference is calculated with the mean at baseline for the same group of patients who answered the follow- up ${ }^{*} \mathrm{p}<0.05$ (Pairwise comparison between baseline and week 3, month 3, year 1 and 3) 